Geopolítica(s) Revista de estudios sobre espacio y poder ISSN: 2172-3958

https://dx.doi.org/10.5209/geop.74608

\title{
Muerte y vida de la Región
}

Rogério Haesbaert (2019) Regional-Global. Dilemas de la región y de la regionalización en la Geografía contemporánea. Buenos Aires: CLACSO, Universidad Pedagógica Nacional, 173 pp. ISBN: 978-987-722-412-2.

Un elemento presente de manera constante en las Ciencias Sociales es el de la complejidad de los conceptos que integran las distintas disciplinas. Complejidad que se afronta desde una problematización y revisión continua, e histórica, de los mismos. A discernir la evolución de este proceso para el concepto de región es a lo que está dedicado el presente trabajo del Rogério Haesbaert. Obra que no sólo se centra en un recorrido sistemático sobre los distintos abordajes ontológicos y epistemológicos al concepto de región, y a sus imbricaciones en la evolución de la disciplina geográfica, sino que busca aportar una propuesta y una síntesis superadora de muchos de los debates en los que se ha centrado la disciplina en este sentido.

El trabajo de Haesbaert, como bien expone su título, se centra en los dilemas y debates en torno al significado, conceptualización y uso del término región, así como a la exposición de una propuesta propia para abordar el mismo, a través de una obra con tres partes bien diferenciadas. En este sentido, el autor fija un objetivo claro, que se aprecia en todo el recorrido del libro, el de "explicar la cuestión o la problemática en la que estamos involucrados" antes de elegir una definición conceptual aplicable (p.146). Así, el recorrido que hace el libro mantiene la idea de Viales Hurtado cuando expone la necesidad de una perspectiva compleja para definir la región ${ }^{1}$. De nuevo, complejidad y problematización como base para el trabajo en la Ciencias Sociales.

En la primera parte del libro, el autor, se centra en realizar un recorrido por los distintos abordajes teóricos que ha tenido la región para exponer así un debate evolutivo sobre su conceptualización. Haesbaert considera que la cuestión regional ha retomado su fuerza en los últimos años debido a una suerte de doble deliberación, por un lado, social/real y, por otro, académica/teórica (p.21). La presión desde los procesos sociopolíticos y su caracterización y desde los debates académicos y sus diversas formulaciones, habría puesto a la región y a la regionalización en el centro de la disciplina. Una posición que, como se verá a lo largo de la obra, supone un constante diálogo con otros conceptos preeminentes como espacio, territorio y escala.

1 Ronny J. Viales Hurtado: La región como construcción social, espacial, política, histórica y subjetiva. Hacia un modelo conceptual/relacional de historia regional en América Latina, Geopolitica(s). Revista de estudios sobre espacio y poder, 1(1), 2010, 157-172. 
El desarrollo de esta evolución conceptual no se realiza en abstracto sino con una vinculación constante a la evolución de la Geografía como disciplina, así como a los distintos enfoques hegemónicos en cada momento. Esto lleva al autor a, primero, destacar el carácter polisémico de la región (p.25), segundo, rastrear el concepto desde su origen teórico hasta el momento hegemónico del mismo como unidad de análisis de la disciplina, con la Geografía regional de comienzos del s.XX (p.28), y, por último, a recorrer las distintas "muertes" y "resurrecciones" epistemológicas de la región dentro del devenir académico (p.37).

Este repaso a los inicios de la preocupación intelectual por la región y la búsqueda del centro de la disciplina geográfica, lo hace partiendo del análisis de los planteamientos de autores como Estrabón, Ptolomeo, Bernard Varenius, Humboldt, Ritter, Vidal de la Blache, Carl Sauer y Richard Hartshorne. Esto implica recopilar propuestas que fluyen a través las primeras preocupaciones clásicas (p.30), las consideraciones sobre la idea de una corographia (p.31), los postulados diferenciadores entre una "geografía general" y una "geografía especial" relacionados con Varenius (p.32), la utilización específica del término "geografía regional" con Ritter (p.32) y los planteamientos ligados al enfoque regional de Vidal de la Blache, Sauer y Hartshorne (p.33). A estos autores, Haesbaert, les atribuye un corpus mínimo de puntos en común sobre el enfoque regional, además de la preeminencia del método empírico en sus trabajos, que se engloban en la importancia de la especificidad y la diferenciación, la cohesión interna, la continuidad espacial, la estabilidad y la vinculación de la región con una escala subestatal concreta (p.35). Relación, esta última, con las escalas, que más adelante el autor se encargará de problematizar y complejizar de manera específica.

Esta preocupación por posicionar las elaboraciones teóricas sobre la región como uno de los debates más intensos dentro de la disciplina le permite situar las distintas "muertes" y "resurrecciones" del concepto, y de las teorías asociadas al mismo, a lo largo del tiempo, vinculándolas con el "rediseño de los paradigmas y las teorías que están en la base de las nuevas composiciones filosóficas" (p.38). La crisis de la región estaría entrelazada con los mismos postulados que augurarían el "fin del espacio" o el "fin del territorio" derivados de la crisis del ente territorial por excelencia, el Estado-Nación. Entrelazado con esto, según estas visiones, la presión homogeneizadora del proceso de globalización supondría la irremediable estandarización del proceso geográfico dificultando las singularidades regionales dentro de esa dicotomía entre especificidad/diferenciación y homogeneidad/unificación (p.38).

Aún así, el autor señala que no es posible plantear esta visión unívoca, cerrada y finalizadora de la región puesto que ésta, por su propia naturaleza conceptual y su evolución teórica ligada al desarrollo de la disciplina, habría sido postergada y revitalizada cíclicamente a lo largo del tiempo. El neopositivismo, el marxismo y el globalismo posmoderno habrían firmado en distintos momentos la desaparición de la singularidad regional o de su existencia como objeto de estudio e instrumento de análisis (p.39). Sin embargo, de manera pendular, la revitalización de la región se habría abierto paso a través del postestructuralismo de énfasis local a través de los planteamientos de la "región-lugar" de Nigel Thrift (p.58) y los postulados sobre las identidades regionales (p.59); y de las perspectivas neo-modernas, en las que incluye la idea de "Estado-región" neoliberal de Kenichi Ohmae (p.64), el análisis 
de las biorregiones de base ecológica (p.66), la teoría de la estructuración de Anthony Giddens (p.67), los abordajes neomarxistas donde sitúa a Agnew, Soja, Massey, entre otros (p.69) y los planteamientos críticos del mosaico de las "ciudadesregión" de Scott (p.72). Por lo tanto, siguiendo al autor, la región y los procesos de regionalización serían moldeados epistemológicamente "dentro de un amplio espectro" (p.70), el cual iría desde las visiones más racionales que los ven como un constructo o instrumento metodológico, hasta las visiones más realistas que los conciben como fenómenos socioespaciales objetivos o simbólicos, pasando por planteamientos normativos y/o pragmático políticos relacionados con la planificación y la acción (p.80).

El desarrollo de esta parte central de la obra recoge el recorrido teórico expuesto que viene a certificar la preocupación existente por la región y los procesos de regionalización como elementos difícilmente evitables dentro de las reflexiones geográficas. Partiendo de esta base, Haesbaert busca, en la última parte del libro "abrir nuevas preguntas y señalar posibilidades de futuras profundizaciones" a través de su propuesta de la región como artefacto que pretende aparecer como síntesis superadora del debate entre las posturas realistas e idealistas y material-funcionales (p.91). En este sentido, no se trataría de reducir la región a una "categoría de lo real" ni a una "categoría de análisis" puesto que ésta no debería reducirse a constructos o a prácticas (p.96). En su lugar, la síntesis superadora implicaría ver a la región como producto-productora de los procesos de diferenciación espacial y de las dinámicas de la globalización y la fragmentación, así como algo construido por la actuación de los sujetos sociales (p.92).

Situar a la región en este nivel de conceptualización dentro de la Geografía lleva al autor a tener que desentrañar la vinculación y relación de ésta con otros conceptos vertebradores de la disciplina como son espacio, territorio y escala. Este proceso complejo implica partir de la relación que el concepto de región y de territorio van a establecer con el "concepto maestro" de espacio (p.128). La preocupación por la existencia de un espacio absoluto y un espacio relativo habría sido completada con una concepción relacional del espacio (Harvey) ${ }^{2}$ que giraría sobre la reflexión constante sobre los tres momentos de la trialéctica lefebvriana del espacio ${ }^{3}$. Recorrer este debate filosófico-teórico permite a Haesbaert entender cómo se construyen los conceptos de región y territorio en función de estas concepciones del espacio, y su relación con ellas, para posteriormente sintetizar los distintos planteamientos existentes sobre la forma de vincularlos entre si: como conceptos separados, como términos inclusivos o en base a sus diferencias (p.143).

Dentro de esta búsqueda de dar a la región una entidad propia y relevante como objeto de la disciplina, su vinculación con la escala adquiere una importancia fundamental. La idea que se atisba en la obra es la de marcar una huida con la reducción, identificación más bien, de la región, o de los procesos de regionalización, con una categoría escalar subnacional, subglobal o con una reducción a lo local (p.120). De esta manera, la propuesta sitúa a la región fuera de cualquier encorsetamiento o restricción escalar particular para potenciar las lógicas diferenciadas

2 Para completar esta conceptualización ver David Harvey: Urbanismo y desigualdad social, Madrid, Siglo XXI, 1977.

3 Para completar esta conceptualización ver Henri Lefebvre: The production of space, Oxford, Blackwell, 1991. 
dependiendo del contexto y para situar y dar preeminencia al proceso de regionalización como acción concreta y abstracta de creación de regiones y de definición de escalas (p.125). Se recogen aquí de nuevo los planteamientos centrales de la propuesta del autor que potencian el concepto de región en base a su caracterización como producto y productora.

La síntesis de la propuesta de Haesbaert conlleva la reflexión sobre la vida de la región como hecho no ignorable ni descartable teórica ni empíricamente, tanto por su potencia como concepto hacia el interior de la disciplina, como por su utilidad como instrumento explicativo de los procesos globales:

Si la región y la regionalización no desaparecen, no es solamente porque la diferenciación y/o desigualdad del mundo continúan fuertes, sino también porque en una visión más integrada y vivida y no simplemente funcional y clasificadora de la región continúan vivos los movimientos, las identidades, las representaciones y las políticas (o bloques económicos) llamados regionales (p.145).

Llegado a este punto, siguiendo con la lógica mostrada a lo largo de la obra que sitúa a la región y a los procesos de regionalización dentro de un ciclo constante de invisibilización y revitalización teórica y práctica, el autor enumera los elementos que a su juicio marcarán los debates futuros sobre estos conceptos. De esta manera, la revitalización de los regionalismos y las identidades regionales, el fortalecimiento de las cuestiones ambientales y el biopoder y el papel de la descentralización regional del poder político y económico, serán los puntos centrales que guiarán el debate y que seguirán presionando desde el interior y el exterior de la disciplina para que la preocupación de la región no cese (p.146). Por lo tanto, los dilemas sobre el sentido y el significado de la vida de la región, como objeto de estudio e instrumento de análisis, continuarán siendo una de las preocupaciones del pensamiento geográfico, permitiendo que, al menos desde un punto de vista ontológico y epistemológico, ésta no desaparezca como lágrimas en la lluvia.

Sergio Claudio González García Facultad de Empresa y Comunicación Universidad Internacional de La Rioja Email: sergioclaudio.gonzalez@unir.net https://orcid.org/0000-0002-3499-2728 